\title{
Influenza Surveillance in Russia Based on Epidemiological and Laboratory Data for the Period from 2005 to 2012
}

\author{
${ }^{1}$ Sominina Anna, ${ }^{2}$ Elena Burtseva, ${ }^{1}$ Mikhail Eropkin, ${ }^{1}$ Ludmila Karpova, \\ ${ }^{1}$ Vladimir Zarubaev, ${ }^{1}$ Elizaveta Smorodintseva, ${ }^{1}$ Nadezhda Konovalova, \\ ${ }^{1}$ Daria Danilenko, ${ }^{1}$ Alexandra Prokopetz, ${ }^{1}$ Mikhail Grudinin, ${ }^{1}$ Maria Pisareva, \\ ${ }^{1}$ Pavel Anfimov, ${ }^{1}$ Kirill Stolyarov, ${ }^{1}$ Oleg Kiselev, ${ }^{2}$ Elena Shevchenko, ${ }^{2}$ Valeriya Ivanova, \\ ${ }^{2}$ Svetlana Trushakova, ${ }^{2}$ Nataliya Breslav, ${ }^{2}$ Dmitriy Lvov, ${ }^{3}$ Alexander Klimov, ${ }^{3}$ Ann Moen and ${ }^{3}$ Nancy Cox \\ ${ }^{1}$ WHO National Influenza Centre, Research Institute of Influenza, St.-Petersburg, Russia \\ ${ }^{2}$ WHO National Influenza Centre, D.I Ivanovsky Institute of Virology, Moscow, Russia \\ ${ }^{3}$ Influenza Division, Centers for Disease Control and Prevention, Atlanta, USA
}

Received 2013-07-01, Revised 2013-10-02; Accepted 2013-10-13

\begin{abstract}
Exchange of information on and sharing of influenza viruses through the GISRS network has great significance for understanding influenza virus evolution, recognition of a new pandemic virus emergence and for preparing annual WHO recommendations on influenza vaccine strain composition. Influenza surveillance in Russia is based on collaboration of two NICs with 59 Regional Bases. Most epidemiological and laboratory data are entered through the internet into the electronic database at the Research Institute of Influenza (RII), where they are analyzed and then reported to the Ministry of Public Health of Russia. Simultaneously, data are introduced into WHO's Flu Net and Euro Flu, both electronic databases. Annual influenza epidemics of moderate intensity were registered during four pre-pandemic seasons. Children aged 0-2 and 3-6 years were the most affected groups of the population. Influenza registered clinically among hospitalized patients with respiratory infections for the whole epidemic period varied between 1.3 and $5.4 \%$ and up but to $18.5-23.0 \%$ during the peak of the two pandemic waves caused by influenza $\mathrm{A}(\mathrm{H} 1 \mathrm{~N} 1) \mathrm{pdm} 09$ virus and to lesser extent (2.9 to $8.5 \%$ ) during usual seasonal epidemics. Most epidemics were associated with influenza $\mathrm{A}(\mathrm{H} 1 \mathrm{~N} 1), \mathrm{A}(\mathrm{H} 3 \mathrm{~N} 2)$ and $\mathrm{B}$ co-circulation. During the two pandemic waves (in 2009-2010 and 2010-2011) influenza $\mathrm{A}(\mathrm{H} 1 \mathrm{N1})$ pdm 09 predominated. It was accompanied by a rapid growth of influenza morbidity with a significant increase of both hospitalization and mortality. The new pandemic virus displaced the previous seasonal $\mathrm{A}(\mathrm{H} 1 \mathrm{~N} 1)$ virus completely. As a rule, most of the influenza viruses circulating in Russia were antigenic ally related to the strains recommended by WHO for vaccine composition for the Northern hemisphere with the exception of two seasons when an unexpected replacement of the influenza B Victoria lineage by Yamagata lineage (2007-2008) and the following return of Victoria lineage viruses (2008-2009) was registered. Influenza surveillance in Russia was improved as a result of enhancing capacity to international standards and the introduction of new methods in NICs such as rRT-PCR diagnosis, regular testing of influenza viruses for susceptibility to antivirals, phylogenetic analysis as well as organization of sentinel surveillance in a number of Regional Base Laboratories. Improvements promoted rapid recognition of the appearance a new pandemic virus in the country and enhancement of confirmation tests in investigation of influenza related death cases.
\end{abstract}

Keywords: Influenza, Virus, Morbidity, Hospitalization, Mortality, Laboratory Confirmation, Virus Isolation, Antigenic Properties, Antivirals, Sentinel Surveillance 


\section{INTRODUCTION}

Investigation of regular trends for influenza virus evolution and influenza morbidity control activities are based on influenza monitoring data, analysis of influenza virus antigenic properties, genetic indicators for pathogen city, mutations appearing within the influenza virus genome, susceptibility of the circulating viruses to the current antiviral drugs, as well as population immunity status. Characterization of circulating influenza viruses is essential to predicting future epidemics/pandemics and to address practical public health challenges, such as updating the composition of influenza vaccines for the upcoming epidemic seasons. The main goal of the Russian influenza surveillance system is to provide a national picture of influenza activity in the country. The most important tasks of the surveillance include: monitoring the timing of influenza activity country-wide; characterizing viruses (type, subtypes), responsible for Influenza-Like Illnesses (ILI) and Acute Respiratory viral Infection (ARI) increases; monitoring antigenic changes in circulating influenza viruses; tracking of ILI/ARI in different age groups; determining the intensity and geographic spread of influenza; determining hospitalizations; registration and analysis of influenza associated Severe Acute Respiratory Illness (SARI) and deaths; determining risk groups for SARI development and lethal outcomes.

\section{MATERIALS AND METHODS}

\subsection{The Organizational Structure of Influenza Surveillance in Russia}

Human influenza surveillance in Russia is conducted by the two WHO National Influenza Centers (NIC) in St. Petersburg at the Research Institute of Influenza (RII) and in Moscow at the D.I. Ivanovsky Institute of Virology (IIV) under the Ministry of Public Health of the Russian Federation (MoH). According to the Order of the Federal Service for Customers' Rights Protection and Human Well-Being Surveillance (Rospotrebnadzor) both RII and IIV are assigned a status of Reference Centers for Influenza Monitoring, tasked with diagnostic confirmation especially for lethal cases, virus identification and antigenic analysis. In addition, the WHO NIC at RII also named as the Federal Influenza Center serves and analyzes epidemiological data on morbidity, hospitalization and death cases sent by 49 Regional Bases (RB), entities which are located in different cities of the Russian Federation, accomplish functions of state sanitary- epidemiological surveillance and conduct local management for Rospotrebnadzor. The WHO NIC at IIV as the Center of Ecology and Epidemiology of Influenza obtains the analogous data from 10 additional RBs. This data is forwarded to the WHO NIC at RII, for processing consolidated data for Russia and preparation of consolidated weekly reports for influenza activity and forwards them to $\mathrm{MoH}$, Rospotrebnadzor and back to RBs. Simultaneously data are introduced into the Flu Net and Euro Flu electronic Databases (EDB). Weekly influenza reports are also placed on the RII official website (www. influenza.spb.ru).

Collection of information on clinically-diagnosed influenza and ARI morbidity and relevant hospitalizations between 2005 to 2012 was conducted for age groups 0-2, 3-6, 7-14 and 15 years and older. Separate registration for ILI and ARI cases was introduced since the 2005-2006 influenza season. An automated Web-based data reporting system via the Internet from RBs to RII was developed and implemented in 2009. Intracity information was conducted by e-mail. Epidemic thresholds for each of 59 Russian cities under surveillance were determined using morbidity data for the previous10-year period (from 1994 to 2004) both for the whole population and for each of the above indicated age groups.

To adapt to the European surveillance system, weekly influenza and ARI morbidity analysis by age groups conventionally used in Europe (0-4, 5-14, 15-64, 65 years and older) as well as of influenza intensity, trends and geographic spread in each of 7 Federal Districts of Russia was added to the surveillance system of Russiasince 2009. In collaboration with and support of the WHO Regional Office for Europe an influenza morbidity baseline for Russia was calculated and used for analysis of influenza seasons in Russia since the 2010-2011 season.

\subsection{Structure of Routine Epidemiological Surveillance}

In Russia, ILI and ARI surveillance are on the list of notifiable condition srequiredto be reported by ambulatory or hospital physicians for primary visits of patients for medical care. No standardized case definition for SARI and ILI/ARI was used in the traditional surveillance system. ILI diagnosed by servicing clinicians on the following symptoms: Increased body temperature, headache, myalgia or weakness and one or more of 3 respiratory symptoms such as cough, sore throat or shortness of breath. The data on ILI and ARI morbidity are accumulated in the local medical centers- 
Rayon Outpatient Clinics (ROC). Weekly data from ROCs are sent to a local Federal Budget Organization "Center for Hygiene and Epidemiology" where data from all ROCs of a city are aggregated and sent to the appropriate RB. Accumulated morbidity and mortality data are submitted by RBs to RII not later than Monday of a following week. RII accumulates and analyzes the weekly data obtained from the RBs each Tuesday and sends the resulting report to Rospotrebnadzor and the Ministry of Healthcare of the Russian Federation. Integrated weekly analysis of laboratory surveillance, epidemiological and sentinel surveillance data are directed to these authorities each Wednesday during the influenza season.

\subsection{Morbidity Index and Analysis}

Morbidity index is calculated as number of all clinically diagnosed both outpatients and inpatients with ILI and ARI per 10000 population of each age group. Growth rate in percent is determined by the formula: (AB)/Bx100, where A-morbidity for analyzed week, Bmorbidity for previous week.

ILI and ARI morbidity data () entered by RBs into RII electronic databases and analyzed automatically by the RII. Data for each of 59 cities are compared with weekly epidemic thresholds and with morbidity data for the previous week to determine the percent increase in morbidity.

\subsection{Lethality Index}

Is calculated as a percent of laboratory-confirmed influenza-related deaths among inpatients (mainly) and outpatients in each age group from the number of ARI\&ILI patients for an analyzed age group.

\subsection{Criteria Determining the Start of an Influenza Epidemic}

Exceeding (higher than 20\%) the influenza epidemic thresholds accompanied by an increase of weekly morbidity growth rates and laboratory detection of influenza cases are recognized as the main criteria of the beginning of the influenza epidemic period. For evaluation of the clinical severity of influenza epidemic hospitalization rates for whole epidemic period are determined by the formula: C/Dx100, where $\mathrm{C}$ is the number of hospitalized patients with influenza diagnosis, $\mathrm{D}$ is the number of hospitalized patients with influenza and ARI diagnosis in total. Etiology of the epidemic and its spread throughout Russia is determined based on the results of integrating morbidity and laboratory data.

\subsection{The Main Components of Influenza Surveillance}

WHO NICs in Russia use a multiple component national surveillance system for influenza that includes laboratory virological data, registration of ILI and ARI and hospitalization and mortality data mainly for the period from October to May. This period is extended to include the period from June to September in the case of the emergence of a new pandemic virus. In addition, the sentinel surveillance system for Severe Acute Respiratory Infection (SARI) among hospitalized patients and ILI/ARI among outpatients was organized. It was conducted in 9 RBs located in different Federal Districts of Russia in 2010-2011 season to determine risk groups and factors complicating influenza infection. Laboratory surveillance includes a number of components such as virus isolation, antigenic and genetic analysis, testing for susceptibility of new isolates to antiviral drugs (oseltamivir, zanamivir, rimantadine) and laboratory diagnosis tests using rRTPCR and Immune Fluorescent Assay (IFA).

\subsection{Sentinel Surveillance (SS)}

"Methodological Recommendations for Sentinel Hospital Based Laboratory and Epidemiological Surveillance for Influenza" were developed in accordance with "WHO Regional Office for Europe Guidelines for Influenza Surveillance in Humans" (2009) by the WHO NIC at RII and approved by Rospotrebnadzor in 2009. This highly specific separate case-based surveillance was organized and introduced in 9 of 59 RBs since the 2010-2011 season with the aim of more detailed analysis of clinical peculiarities of influenza in dependence of etiology, concomitant somatic pathology, pregnancy, previous vaccination, antiviral treatment. A total 18 hospitals and 12 ambulatory care clinics participated in SS. rRT-PCR exclusively was used for influenza diagnosis in SS.

\subsection{Case Definition of SARI and ILI Standardized in Sentinel Surveillance System (SS)}

SARI diagnosis (with onset of illness during the previous 7 days that results in hospitalization) was used for analysis in SS system exclusively. Criterions for SARI in adults and children aged 5 years old and more included: fever $>38^{\circ} \mathrm{C}$ and cough or sore throat and shortness of breath or difficulty breathing. Criterions for SARI in children less than 5 years old were breathing faster than 40 breaths $\min ^{-1}$ (ages 1-5 years), faster than 50 breaths $\min ^{-1}$ (ages 2-12 months) and any of the following general danger signs such as unable to drink or 
breastfeed, vomits, convulsions, lethargic or unconscious, chest in drawing or stridor in a calm child. In SS system ILI diagnosed in a person with sudden onset of fever $>38^{\circ} \mathrm{C}$ and cough or sore throat in the absence of other diagnosis. ARI diagnosed in a person with sudden onset and at least one of the following four respiratory symptoms: cough, sore throat, shortness of breath, coryza and a clinician's judgment that the illness is due to an infection.

\subsection{Determination of Virus Susceptibility to Antivirals}

Susceptibility to oseltamivir carboxyl ate was conducted in NICs by measuring activity of neuraminidase in the reaction with a fluorogenic substrate (WHO, 2011) and RFLP test (Guo et al., 2009). Testing the inhibition of virus reproduction in MDCK cells in the presence of rimantadine was employed as well (Smee et al., 2009). Molecular genetic analysis of NA and Mgenes was conducted to detect amino acid substitutions responsible for the appearance of drug-resistant variants: viruses resistant to oseltamivir and rimantadine respectively.

\subsection{Sending Isolates to WHO CCs}

To improve global surveillance for influenza a total of 27 to 193 representative Russian strains and influenza virus drift variants were sent every year by the two NICs to the WHO CC in Atlanta, USA (751 viruses for the 7 years period). Between 23 and 87 additional influenza strains per year (367 viruses for the whole period) were forwarded by RII to the WHO CC in London, UK.

\subsection{Population Immunity Investigation}

Is conducted in the Regional Virological Laboratories (RVL) of RII in accordance with the Order of Rospotrebnadzor \#373 as of March 31, 2005 "On Improvement of the Epidemiological Surveillance and Control of Influenza and Acute Respiratory Viral Infections". Analysis of 100 sera obtained from healthy adult blood donors aged 18-63 years in the pre-epidemic (in October) and post-epidemic (in April) periods are performed in RVLs each year. All results are sent to the NIC at RII to determine Geometric Mean Titers (GMT) of antibodies and Percent of Positive Humans (PPH) with antibody HI titer 1:32 or greater to seasonal influenza A (H1N1), (H1N1) pdm 09 (since the season 2009-2010), A(H3N2) and to influenza B viruses. Virus antigens used were inactivated and were antigenicallylike the strains recommended to be included in influenza vaccine composition for the respective seasons. Simultaneously, PPH and GMT to the viruses antigenic ally related to causative agents of previous pandemics, such as A/swine/Iowa/15/30 (Hsw1N1), A/Singapore/1/57(H2N2) were determined. Reassortant vaccine strain NIBRG-14 containing HA of highly pathogenic avian influenza virus A/Vietnam/1194/04 (H5N1) with deleted polybasic amino acid sequence was also used in population immunity investigations.

\subsection{Virological Surveillance}

Virus isolation was conducted by WHO NICs using MDCK cells and chicken embryos in parallel. In RVLs virus isolation was performed in MDCK cells only. Standard operating procedures were followed as published in Methodological recommendations "Influenza Virus Isolation in Cell Cultures and Chick Embryos and their Identification" prepared by WHO NICs in Russia (approved by Rospotrebnadzor in 2005). Briefly, nasal smears from the ILI and ARI patients suspended in transport medium (UTM-RT, Copan, USA) were used for infecting MDCK or MDCK/SIAT 1 cells grown in Eagle's MEM with 5\% of Fetal Bovine Serum (FBS) containing TPCK trypsin $(2 \mu \mathrm{g}$ $\left.\mathrm{mL}^{-1}\right)$. On the $3 \mathrm{rd}$, 4th, 5th and 6th days cells were examined using an inverted microscope (UNICO, USA) and if CPE was observed the medium was collected and used for HA detection and titration. PCR positive clinical samples and MDCK/SIAT1 cells were used since the season 2011-2012. The chicken embryos were infected by inoculation of clinical samples into both the amniotic and allantoic cavity. After $72 \mathrm{~h}$ of incubation at $34^{\circ} \mathrm{C}$ allantoic and amniotic fluids were sampled for HA determination. In the case of positive results the HA containing medium was divided into two parts: One was used for the second passage of the virus in chicken embryos or in MDCK cells and the second one was used for investigations and lyophilization. Negative samples were used for the second "blind" passage in both systems. WHO/CDC kits and immune rat sera to representative influenza strains prepared in NICs' laboratories were used in the investigation of antigenic properties of influenza viruses isolated in Russia.

\subsection{IFA Diagnosis}

Methodological recommendations in "Rapid Diagnosis of Influenza and other ARI by Immunofluorescent Assay", which had been approved by Rospotrebnadzor in 2005, were used as guidelines in IFA investigations conducted by RVLs. This includes direct investigation of acetone-fixed, pre-washed with PBS nasal epithelial cells taken from the ILI\&ARI patients in the first 3 days of infection and stained with FITCconjugated antibodies to contemporary influenza $\mathrm{A}(\mathrm{H} 1 \mathrm{~N} 1), \mathrm{A}(\mathrm{H} 3 \mathrm{~N} 2)$ and B viruses ("Diagnostic Reagent Venture" at RII, St.-Petersburg, Russia). 


\subsection{4. rRT-PCR Diagnosis}

Was introduced in RVLs since the 2008-2009 season. Investigation of clinical samples was conducted using instructions enclosed in "AmpliSense Influenza virus A/BFL", "AmpliSense Influenza virus A type FL" and "AmpliSense Influenza virus A/H1-swine-FL" kits designed for the detection of influenza virus RNA types A and $\mathrm{B}$, sub typing of seasonal influenza $\mathrm{H} 1 / \mathrm{H} 3$ and for detection of influenza $\mathrm{H} 1 \mathrm{pdm} 09$ virus respectively (FBUN "Central Institute of Epidemiology", Moscow, Russia).

\section{RESULTS}

\subsection{Results of Influenza Epidemiological Surveillance}

\subsubsection{The Main Parameters of Epidemics and Morbidity Indices}

During the period from 2005 to 2009 seasonal influenza epidemics of moderate intensity characterized by relatively low morbidity, hospitalization and lethality indices were registered annually (Fig. 1 and 2). During three seasons (2005-2006, 2006-2007 and 2009-2010) influenza epidemics spread from the East to the West, but during four seasons (2007-2008, 2008-2009, 2010-2011 and 20112012) epidemics were observed to move in two opposite directions (both eastwards and westwards). For example, during the 2007-2008 season influenza A(H1N1) virus first appeared in the West and subsequently spread to the East while influenza B virus spread concurrently from the East to the West. During the influenza season in 2008-2009, the influenza $\mathrm{A}(\mathrm{H} 3 \mathrm{~N} 2)$ epidemic moved from the West, while the influenza $\mathrm{A}(\mathrm{H} 1 \mathrm{~N} 1)$ epidemic started in the Eastern part of the country. The influenza pandemic A(H1N1) pdm 09 virus was detected for the first time in the Far East and from there spread to the cities of Siberia, Urals and later to the European part of the country. In the 2010-2011 season influenza $\mathrm{A}(\mathrm{H} 1 \mathrm{~N} 1)$ pdm 09 virus started to spread from the West, while influenza B activity was registered in the East of the country. In the past 7 years, the start of the epidemic influenza activity generally occurred during weeks 3-5. The 2009-2010 season appeared to be an exception characterized by unusually early pandemic morbidity which registered in early October 2009 (Table 1).

The peak of morbidity was registered usually 5-7 weeks after the start of influenza activity followed by a gradual decrease of epidemic intensity to non-epidemic levels 6-9 weeks later. The weekly morbidity index at the peak of annual epidemics varied in the range from 0.76 to $1.04 \%$ for the whole population, but it increased by 1.3-1.9 times during the two pandemic waves. Both morbidity indices and duration of the seasonal epidemic in different age groups showed the highest impacton children aged 0-2 and 3-6 years.

Median morbidity of ILI and ARI during the period of circulation of seasonal influenza $\mathrm{A}(\mathrm{H} 1 \mathrm{~N} 1), \mathrm{A}(\mathrm{H} 3 \mathrm{~N} 2)$ and $\mathrm{B}$ viruses didn't differ significantly, but became much higher during the pandemic period both for the whole population, school children of 7-14 years and groups of adults 15 years and older. At the same time, morbidity values in young children (0-2 and 3-6 years) were quite comparable with indices registered during seasonal epidemics (Fig. 3).

\subsection{Hospitalization Indices}

Annually during seasonal epidemics 69.6 to 86.7 thousand patients with «influenza» and «ARI» clinical diagnosis were hospitalized, during the first and second pandemic waves it increased up to 150.9 and 122.1 thousands. Influenza registered clinically among hospitalized patients with respiratory infections for the whole epidemic period varied between 1.3 and $5.4 \%$ but increased up to 14.1 and $12.9 \%$ during the seasons 2009 2010 and 2010-2011. On the peak of two pandemic waves caused by influenza $\mathrm{A}(\mathrm{H} 1 \mathrm{~N} 1)$ pdm 09 virus hospitalization index incresed up to $18.5-23.0 \%$ from 2.9 to $8.5 \%$ during usual seasonal epidemics (Table 1).

\subsection{Influenza-Related Death Cases and Lethality}

During the circulation of seasonal influenza viruses only a few influenza-related deaths (3-6 cases per year) occurring mainly among young children and elderly persons were registered. During the first pandemic wave lethality due to influenza was found to increase sharply reaching $0.03 \%$ for the overall population (Table 1 and Fig. 2), the lowest lethality index $(0.001 \%)$ was registered among children aged 3-6 years, this index was 2-fold higher among children aged 0-2 and 7-14 years; the highest lethality $(0.06 \%)$ was registered among adult populations aged 15-64 years. The majority of deaths were registered at the peak of the season and during two subsequent weeks (weeks 47-49.2009). The percent distribution of all registered rRT-PCR confirmed influenza death cases by age groups $(0-2,3-6,7-14,15$ 64 and $\geq 65$ years) during the season 2009-2010 was estimated as $1.4,1.4,1.8,92.8$ and $2.4 \%$, respectively. Risk factors for influenza-related deaths included underlying infections, chronic diseases and pregnancy. Chronic hepatitis, pancreatitis and renal diseases were found in $8.3 \%$ of cases, cardiovascular pathology in $7.0 \%$, immunodeficiency diseases in $3.5 \%$, endocrine dysfunctions in $3.7 \%$, obesity in $6.7 \%$, encephalopathy in $2.1 \%$ and pregnancy in $4.7 \%$. 


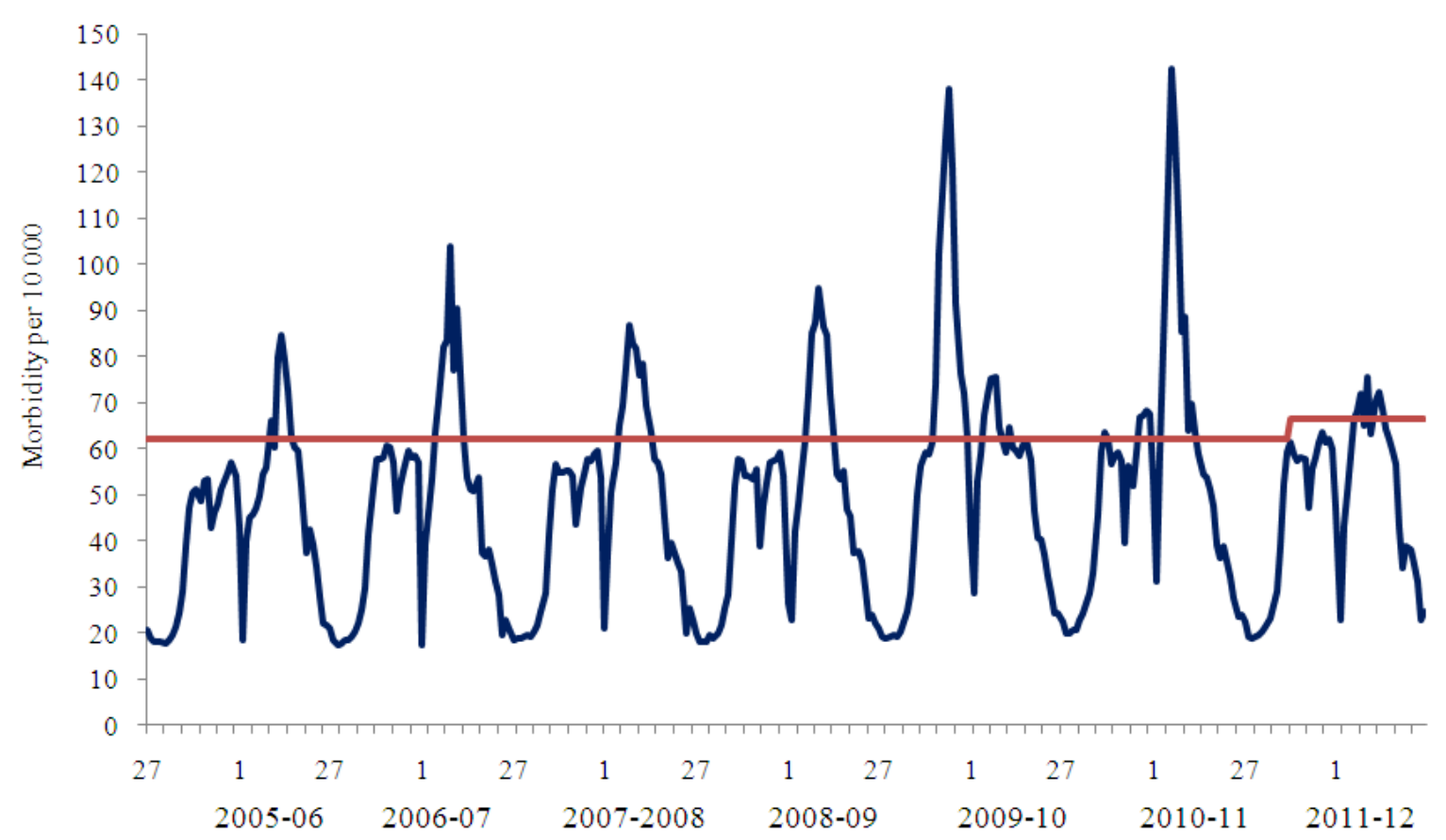

Fig. 1. Population based surveillance for ILI\&ARI morbidity in the russian federation for the period from 2005-2006 to 2011-2012 seasons according to data of two WHO NICs of Russia

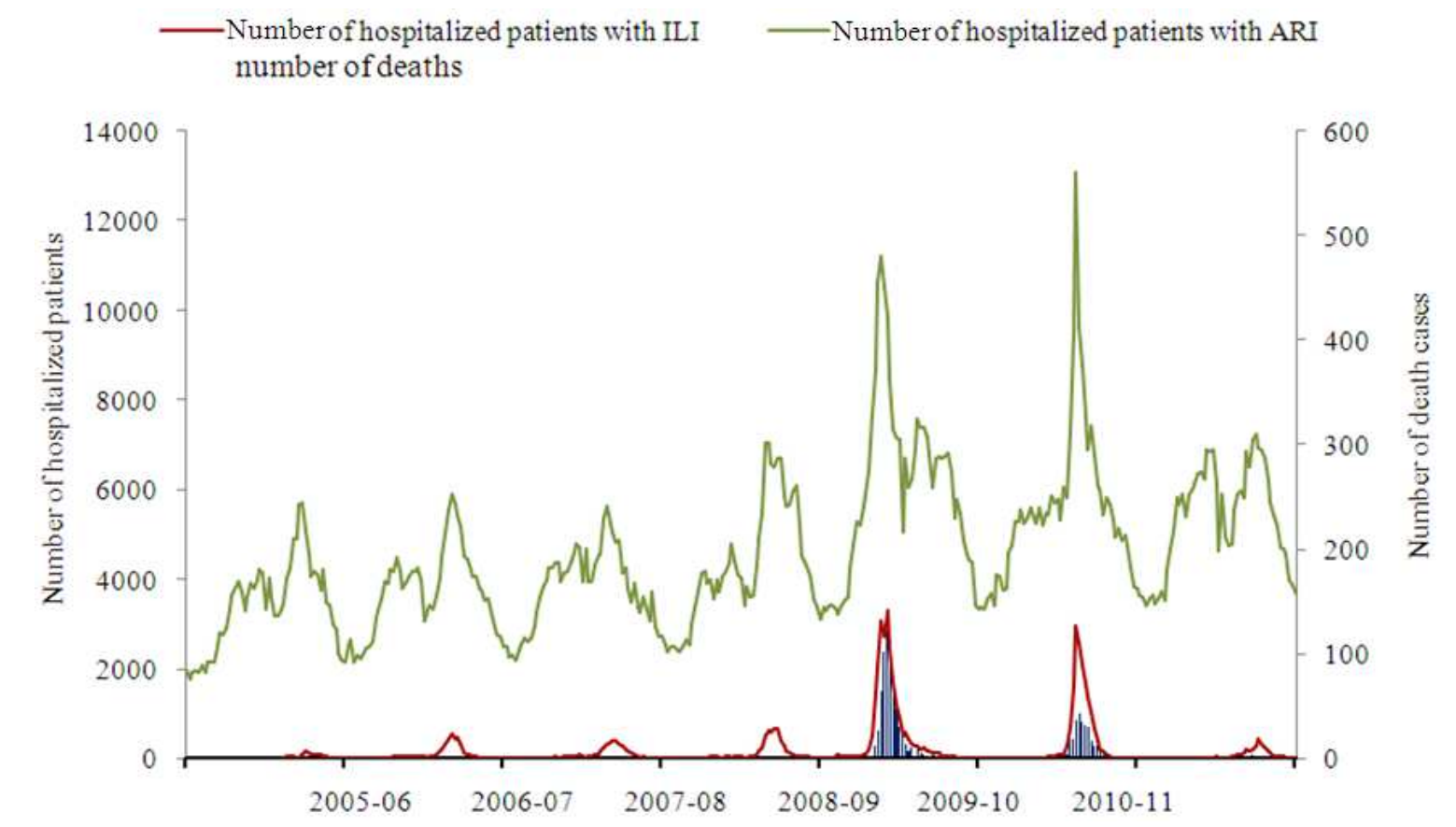

Fig. 2. Population based surveillance for ILI and ARI hospitalization and influenza laboratory-confirmed death cases for the period from 2005-2006 to 2011-2012 seasons according to data reported by 59 cities of the RF collaborating with WHO NICs 
Sominina Anna et al. / American Journal of Infectious Diseases 9 (3): 77-93, 2013

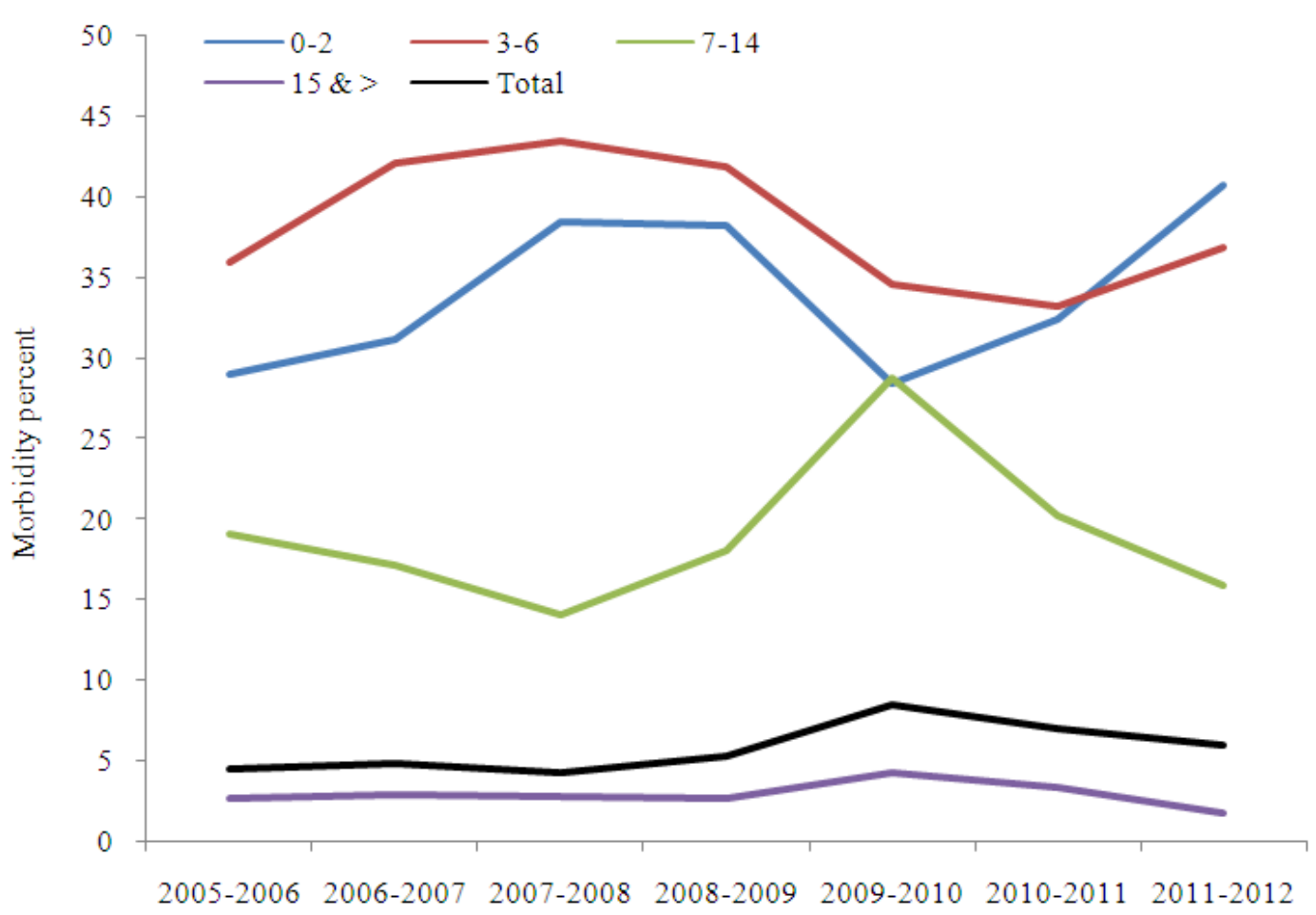

Fig. 3. Influenza and ARI morbidity in different age groups of Russian population during seasonal influenza epidemics and pandemic for the period from season 2005-2006 to 2011-2012

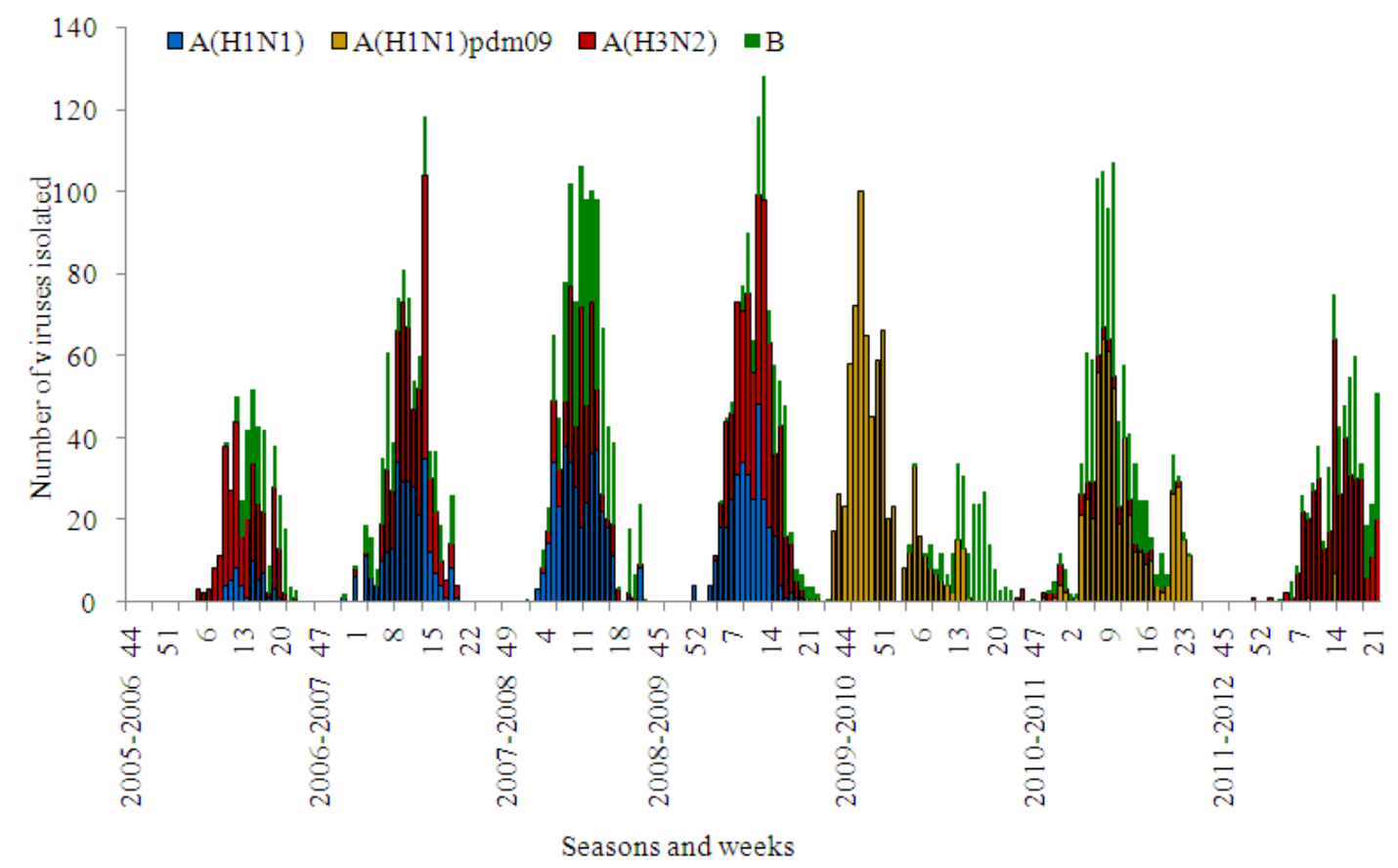

Fig. 4. Influenza A(H1N1), A(H3N2), A(H1N1) pdm and B virus isolation in Russia for period from 2005-2006 to 2011-2012 seasons 
Sominina Anna et al. / American Journal of Infectious Diseases 9 (3): 77-93, 2013

Table 1. Epidemiological parameters of influenza epidemics in Russia for the period 2005-2012 according to the primary data on morbidity, hospitalization and death cases reported by collaborating Regional Basesand analyzed at Research Institute of Influenza

\begin{tabular}{|c|c|c|c|c|c|c|c|c|}
\hline \multirow[b]{2}{*}{ Indices } & & \multicolumn{7}{|c|}{ Epidemic Seasons } \\
\hline & & 2005-2006 & 2006-2007 & $2007-2008$ & 2008-2009 & $2009-2010$ & 2010-11 & 2011-12 \\
\hline \multirow{2}{*}{\multicolumn{2}{|c|}{$\begin{array}{l}\text { Week of start - end of the epidemic in Russia } \\
\text { Duration of the epidemic in weeks }\end{array}$}} & $05-22$ & $04-17$ & \multicolumn{2}{|c|}{$03-1704-17$} & $40-03$ & $01-14$ & $05-12$ \\
\hline & & 18 & 14 & 15 & 14 & 17 & 14 & 16 \\
\hline \multicolumn{2}{|c|}{ Number of week when epidemic peaked } & 13 & 9 & 8 & 10 & 47 & 8 & 10 \\
\hline Average for cities duration of & Total population & 5,6 & 5,1 & 5,4 & 5,3 & 6,8 & 5,2 & 6,2 \\
\hline influenza epidemic (weeks) by & $0-2$ years & 6,1 & 6,6 & 6,7 & 7,4 & 4,4 & 4,7 & 6,9 \\
\hline \multirow[t]{3}{*}{ age groups } & $3-6$ years & 7,5 & 7,7 & 8,2 & 8,2 & 5,0 & 4,7 & 6,4 \\
\hline & $7-14$ years & 7,3 & 6,5 & 5,8 & 6,6 & 6,7 & 4,9 & 6,4 \\
\hline & 15 years\&older & 5,5 & 4,6 & 5,1 & 4,7 & 6,7 & 4,7 & 4,0 \\
\hline \multirow{5}{*}{$\begin{array}{l}\text { Percent of cities involved in the } \\
\text { epidemic by age group }\end{array}$} & In total & 77,9 & 77,9 & 84,7 & 93,2 & 98,3 & 96,6 & 28,8 \\
\hline & $0-2$ years & 61,0 & 77,9 & 71,2 & 86,4 & 89,8 & 76,3 & 22,0 \\
\hline & $3-6$ years & 84,7 & 86,4 & 88,1 & 86,4 & 91,5 & 93,2 & 54,2 \\
\hline & $7-14$ years & 88,1 & 77,9 & 86,4 & 89,8 & 100 & 96,6 & 52,5 \\
\hline & 15 years \& older & 59,3 & 61,0 & 69,5 & 74,6 & 98,3 & 94,9 & 11,9 \\
\hline \multicolumn{2}{|l|}{$\begin{array}{l}\text { Percent of ILI and ARI morbidity } \\
\text { at the peak of the epidemic }\end{array}$} & 0,85 & 1,04 & 0,87 & 0,95 & 1,38 & 1,43 & 0,76 \\
\hline \multirow{5}{*}{$\begin{array}{l}\text { Average ILI \& ARI morbidity } \\
\text { (percent of population in each age } \\
\text { group) for the epidemic period } \\
(\mathrm{M} \pm 2 \mathrm{~m})\end{array}$} & Total population & $4,9 \pm 0,6$ & $5,0 \pm 0,6$ & $5,2 \pm 0,7$ & $5,3 \pm 0,8$ & $8,5 \pm 0,7$ & $7,1 \pm 0,7$ & $5,9 \pm 0,4$ \\
\hline & $0-2$ years & $27,7 \pm 3,7$ & $32,4 \pm 5,1$ & $34,2 \pm 6,0$ & $39,7 \pm 5,8$ & $32,6 \pm 8,0$ & $32,9 \pm 4,5$ & $40,2 \pm 4,4$ \\
\hline & 3-6 years & $34,1 \pm 4,2$ & $37,1 \pm 4,3$ & $41,9 \pm 4,9$ & $44,6 \pm 5,7$ & $36,0 \pm 3,7$ & $33,4 \pm 4,2$ & $36,9 \pm 4,6$ \\
\hline & $7-14$ years & $19,7 \pm 2,9$ & $17,8 \pm 1,9$ & $13,7 \pm 1,9$ & $17,5 \pm 2,8$ & $29,0 \pm 2,5$ & $21,0 \pm 2,6$ & $15,8 \pm 1,8$ \\
\hline & 15 years $\&$ older & $2,7 \pm 0,4$ & $2,6 \pm 0,4$ & $2,6 \pm 0,4$ & $2,6 \pm 0,4$ & $4,3 \pm 0,4$ & $3,4 \pm 0,4$ & $1,7 \pm 0,1$ \\
\hline \multirow[t]{2}{*}{ Number of hospitalized patients } & Influenza & 1023 & 3318 & 3314 & 4656 & 21319 & 15742 & 2619 \\
\hline & Influenza \& ARI & 77344 & 69617 & 71214 & 86710 & 150924 & 122082 & 101429 \\
\hline \multirow[t]{2}{*}{$\begin{array}{l}\text { Percent of hospitalized patients } \\
\text { with ILI clinical diagnosis }\end{array}$} & $\begin{array}{l}\text { For the epidemic } \\
\text { period * }\end{array}$ & 1,3 & 4,8 & 4,7 & 5,4 & 14,1 & 12,9 & 2,6 \\
\hline & $\begin{array}{l}\text { On the peak } \\
\text { of epidemic }\end{array}$ & 2,9 & 8,4 & 6,8 & 8,5 & 23,0 & 18,5 & 5,9 \\
\hline \multicolumn{2}{|l|}{$\begin{array}{l}\text { Number of laboratory confirmed } \\
\text { influenza deaths cases }\end{array}$} & 3 & 4 & 6 & 4 & 622 & 264 & 7 \\
\hline \multicolumn{2}{|l|}{$\begin{array}{l}\text { The direction of the epidemic } \\
\text { spread in the country }\end{array}$} & $\begin{array}{l}\text { From East } \\
\text { to West }\end{array}$ & $\begin{array}{l}\text { From East } \\
\text { to West }\end{array}$ & $\begin{array}{l}\text { In both } \\
\text { directions }\end{array}$ & $\begin{array}{l}\text { In both } \\
\text { directions }\end{array}$ & $\begin{array}{l}\text { From East } \\
\text { to West }\end{array}$ & $\begin{array}{l}\text { In both } \\
\text { directions }\end{array}$ & $\begin{array}{l}\text { In both } \\
\text { directions }\end{array}$ \\
\hline
\end{tabular}

*- beginning from the start to the end of epidemic on the territory of 59 cities under surveillance with population number of 48.5 millions of people

During the second pandemic wave (2010-2011) the lethality index for the total population was 10 -fold lower $(0.003 \%)$, including a 4.2-fold decrease among persons over 65 years and a 20 -fold decrease among schoolchildren aged 7-14 yearsin comparison with season 2009-2010. Changes in the age structure of deaths were found as well. The percent of influenza-related deaths increased for children 0 2 years up to $2.3 \%$ and for adults $\geq 65$ years up to $8.3 \%$ but it decreased for schoolchildren from 1.8 to $1.1 \%$. Meanwhile percent of deaths for the group 15-64 years of age decreased slightly and was estimated as $86.6 \%$ of lethal cases.. Influenza death cases were registered more often among patients with such underlying conditions as encephalopathy and organic brain lesions (increased 5.8fold), endocrine dysfunctions and cardiovascular pathology (increased 3.9-fold); chronic diseases of the respiratory tract (ncreased3-fold),hepatitis, pancreatitis and renal diseases (increased 2.3-fold) and immunodeficiency diseases (increased 1.9-fold.

\subsection{Etiological Monitoring of Influenza}

During recent years regular isolation of seasonal influenza viruses usually started by weeks 3-4 of January and rarely began earlier in December. All the epidemicsin seasons 2005-2006 to 2008-2009 had mixed etiology associated with co-circulation of influenza A(H1N1), $\mathrm{A}(\mathrm{H} 3 \mathrm{~N} 2)$ and $\mathrm{B}$ viruses with a prevalence of influenza $\mathrm{A}(\mathrm{H} 3 \mathrm{~N} 2)$ virus in 2005-2006 and 2011-2012 seasons (Table 2). Seasonal influenza $\mathrm{A}(\mathrm{H} 1 \mathrm{~N} 1)$ or influenza B viruses were secondary in the frequency of isolation for the period from 2005-2006 to 2008-2009. Thus, in the prepandemic period alternation in intensity of circulation of influenza seasonal $\mathrm{A}(\mathrm{H} 1 \mathrm{~N} 1)$ and $\mathrm{B}$ viruses with a prevalence of $\mathrm{A}(\mathrm{H} 3 \mathrm{~N} 2)$ viruses in some seasons was registered (Fig. 4 and 5). The situation changed sharply with the emergence of influenza $\mathrm{A}(\mathrm{H} 1 \mathrm{~N} 1)$ pdm 09 virus. The first case of the pandemic virus isolation was registered in May 2009 at the WHO NIC in Moscow (Lvov et al., 2009) and later in WHO NIC in St.-Petersburg. 
Table 2. Annual number of influenza viruses isolated in two WHO NICs and collaborating Regional Base Laboratories for the period from 2005-2006 to 2011-2012

\begin{tabular}{|c|c|c|c|c|c|c|c|}
\hline \multirow[b]{2}{*}{ Season } & \multirow{2}{*}{$\begin{array}{l}\text { Number of } \\
\text { Investigated } \\
\text { patients }\end{array}$} & \multirow{2}{*}{$\begin{array}{l}\text { Influenza } \\
\text { viruses } \\
\text { isolated }\end{array}$} & \multicolumn{5}{|c|}{ Type/ subtype of influenza virus } \\
\hline & & & $\mathrm{A}(\mathrm{H} 1 \mathrm{~N} 1)$ & $\mathrm{A}(\mathrm{H} 3 \mathrm{~N} 2)$ & $\mathrm{B}$ & $\mathrm{A}(\mathrm{H} 1 \mathrm{~N} 1) \mathrm{pdm}$ & Total \\
\hline \multirow[t]{2}{*}{ 2005-2006 } & 7372 & Number & 68 & 335 & 181 & 0 & 584 \\
\hline & & Percent* & $12 \%$ & $57 \%$ & $31 \%$ & 0 & $100 \%$ \\
\hline \multirow[t]{2}{*}{ 2006-2007 } & 12513 & Number & 315 & 345 & 181 & 0 & 841 \\
\hline & & Percent & $37 \%$ & $41 \%$ & $22 \%$ & 0 & $100 \%$ \\
\hline \multirow[t]{2}{*}{ 2007-2008 } & 11807 & Number & 356 & 247 & 405 & 0 & 1008 \\
\hline & & Percent & $35 \%$ & $25 \%$ & $40 \%$ & 0 & $100 \%$ \\
\hline \multirow[t]{2}{*}{ 2008-2009 } & 14234 & Number & 316 & 469 & 171 & 2 & 958 \\
\hline & & Percent & $33 \%$ & $49 \%$ & $18 \%$ & $0,0 \%$ & $100 \%$ \\
\hline \multirow[t]{2}{*}{ 2009-2010 } & 11406 & Number & 0 & 0 & 187 & 709 & 896 \\
\hline & & Percent & 0 & 0 & $21 \%$ & $79 \%$ & $100 \%$ \\
\hline \multirow[t]{2}{*}{$2010-2011$} & 11831 & Number & 0 & 65 & 383 & 521 & 969 \\
\hline & & Percent & 0 & $7 \%$ & $40 \%$ & $54 \%$ & $100 \%$ \\
\hline \multirow[t]{2}{*}{ 2011-2012 } & 8008 & Number & 0 & 391 & 192 & 8 & 591 \\
\hline & & Percent & 0 & $66 \%$ & $32 \%$ & $1 \%$ & $100 \%$ \\
\hline
\end{tabular}

*-percent from total number of viruses isolated is indicated

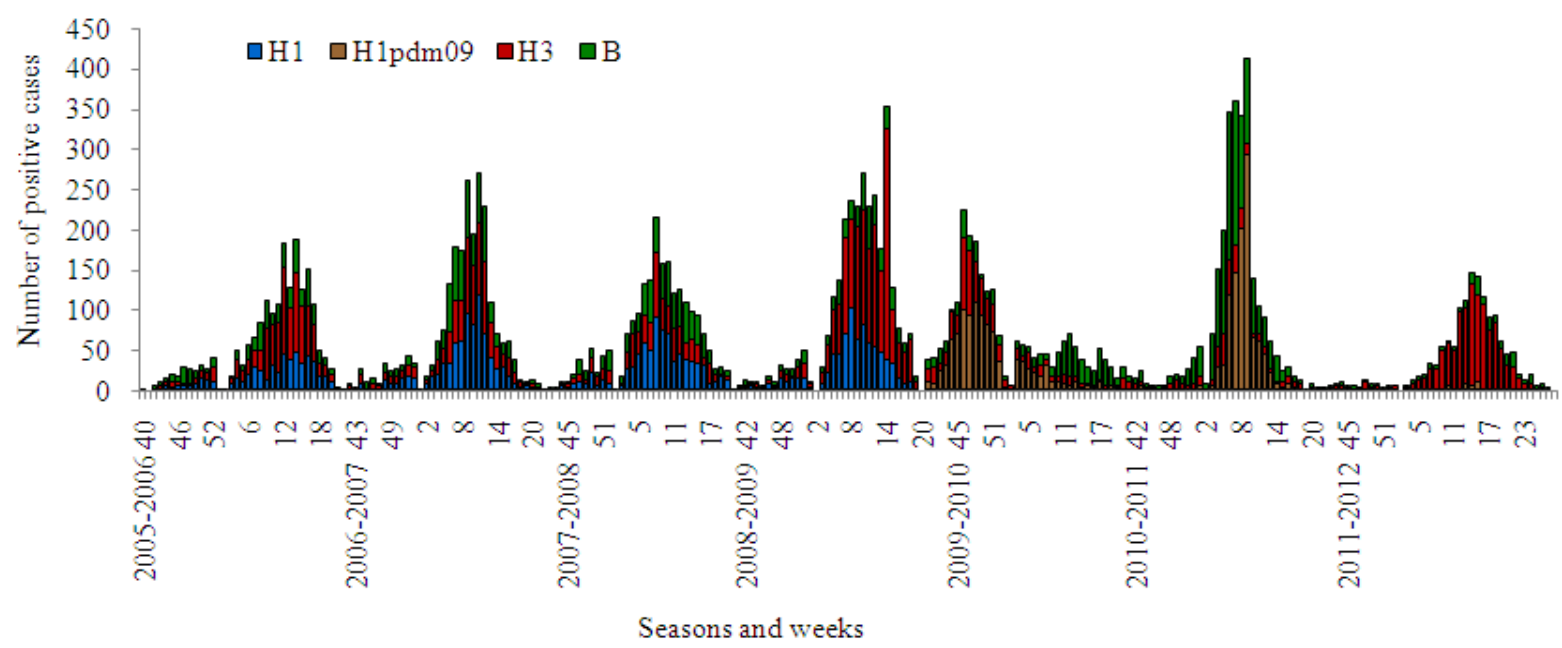

Fig. 5. Influenza etiological monitoring in Russia using immune fluorescent analysis of clinical materials for period from 2005-2006 to 2011-2012 seasons

During the spring and summer months A(H1N1) pdm 09 was detected by rRT-PCR sporadically in ILI cases mostly in passengers arriving from affected countries. A sharp increase in the number of diagnosed influenza A(H1N1) pdm 09 cases accompanied by growth of epidemic morbidity was observed in October 2009 (Fig. 4-6). This rapid rise in cases was seen first in the cities of the Far East with spread of the pandemic virus toward the West through Siberia and the Urals to the European part of the country. In November-December the majority of Russian cities appeared to be affected by the pandemic with an unusually high increase of influenza morbidity and mortality. Both virus isolation and rRTPCR data indicated exclusive circulation of the pandemic virus during this time. By the end of December and particularly after two weeks of the New Year and Christmas vacations, the rate of pandemic virus diagnosis and associated morbidity began to decrease. Influenza $B$ virus appeared and circulated with moderate intensity during the winter and part of the spring. It is interesting that as in the previous pandemics the new influenza $\mathrm{A}(\mathrm{H} 1 \mathrm{~N} 1)$ pdm 09 virus completely supplanted seasonal influenza $\mathrm{A}(\mathrm{H} 1 \mathrm{~N} 1)$ virus circulating earlier (Pica et al., 2012). 


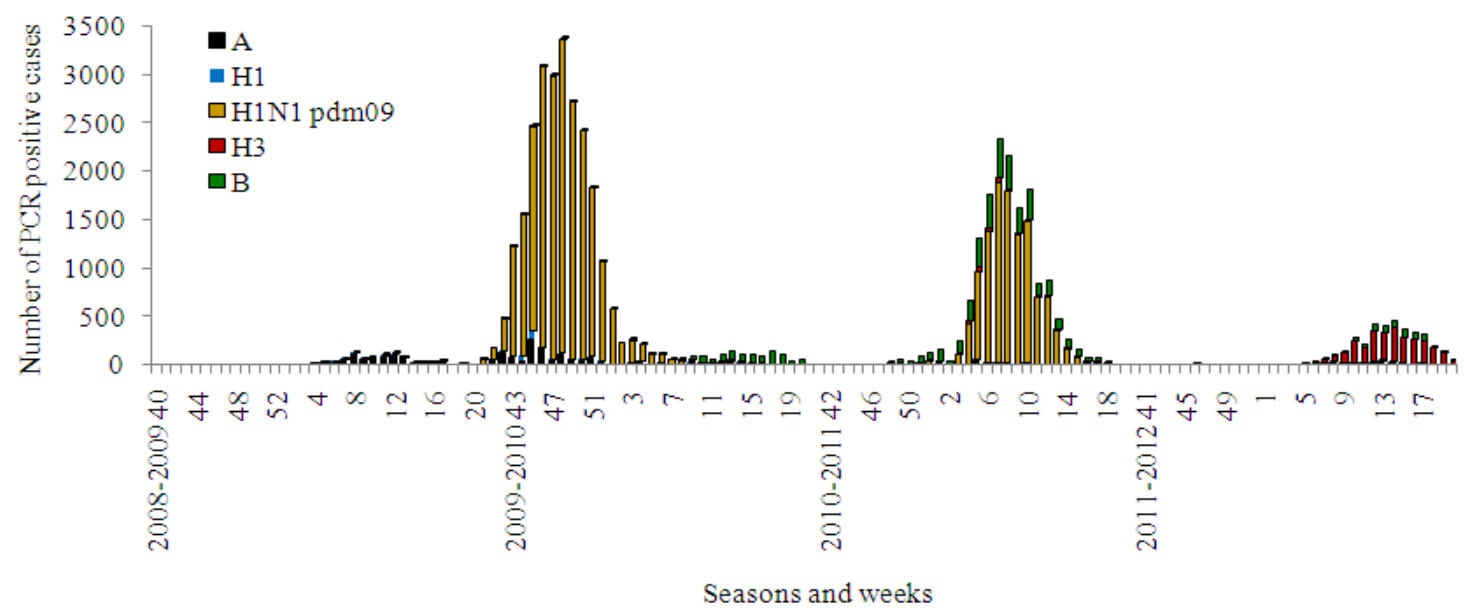

Fig. 6. Influenza etiological monitoring in Russia using rRT-PCR analysis of clinical materials for the period from 2008-2009 to 2011-2012 seasons

Table 3. Population immunity data according to RBLs data for the period 2009-2012.

\begin{tabular}{|c|c|c|c|c|c|c|c|c|}
\hline \multirow[b]{2}{*}{ Indices testing } & \multirow[b]{2}{*}{ Date of blood } & \multirow{2}{*}{$\begin{array}{l}\text { Number } \\
\text { of blood } \\
\text { samples }\end{array}$} & \multicolumn{6}{|c|}{ Antibodies to influenza viruses } \\
\hline & & & H1pdm09 & $\mathrm{H} 2$ & H5 & H1 & $\mathrm{H} 3$ & $\mathrm{~B}$ \\
\hline \multirow[t]{6}{*}{ Mean Geometric titers } & October 2009 & 2000 & 3,2 & 1,6 & 0,3 & 27,3 & 39,9 & 36,2 \\
\hline & April 2010 & 2400 & 18,3 & 4,1 & 0 & 28,2 & 38,6 & 31,2 \\
\hline & October 2010 & 2700 & 12,3 & 1,5 & 0,6 & 36,7 & 42,6 & 42,8 \\
\hline & April 2011 & 3600 & 25,6 & 5,6 & 0,9 & 42,6 & 43,0 & 46,7 \\
\hline & October 2011 & 3200 & 21,5 & 2,5 & 0,9 & 40,8 & 35,3 & 47,8 \\
\hline & April 2012 & 3200 & 25,7 & 2,6 & 1,1 & 35,2 & 39,3 & 57,9 \\
\hline \multirow{6}{*}{$\begin{array}{l}\text { Percent of persons with } \\
\text { antibody protective titer }\end{array}$} & October 2009 & 2000 & 10,1 & 4,2 & 0 & 66,2 & 68,6 & 66,3 \\
\hline & April 2010 & 2400 & 32,3 & 2,8 & 0,5 & 54,3 & 66,7 & 60,0 \\
\hline & October 2010 & 2700 & 36,2 & 4,0 & 0,1 & 60,2 & 70,4 & 73,5 \\
\hline & April 2011 & 3600 & 54,3 & 3,9 & 0,2 & 68,8 & 68,6 & 71,3 \\
\hline & October 2011 & 3200 & 48,6 & 4,5 & 0,2 & 58,0 & 58,1 & 72,8 \\
\hline & April 2012 & 3200 & 54,6 & 6,4 & 0,2 & 60,1 & 73,6 & 78,8 \\
\hline
\end{tabular}

Note: titers antibodies 1:32 and more in hemagglutination inhibition test

However, influenza $\mathrm{A}(\mathrm{H} 3 \mathrm{~N} 2)$ viruses, as occurred in pandemic 1977, retained their epidemic activity and caused epidemics in the next season in North American countries (USA, Canada) (CDCP, 2011). On the contrary, in Russia and most countries of the European region the 2010-2011 epidemic season was mainly caused by the pandemic virus(second pandemic wave) and $\mathrm{A}(\mathrm{H} 3 \mathrm{~N} 2)$ activity didn't increase again in these countries until the 2011-2012 season, when the epidemic was of low intensity. This was partly due to population immunity status. Studies established that $66-68 \%$ of adults in different regions of Russia had protective levels of immunity to seasonal influenza $\mathrm{A}(\mathrm{H} 1 \mathrm{~N} 1), \mathrm{A}(\mathrm{H} 3 \mathrm{~N} 2)$ and $\mathrm{B}$ viruses in October 2009 , but only $10.1 \%$ were positive to influenza $\mathrm{A}(\mathrm{H} 1 \mathrm{~N} 1)$ pdm 09 virus (Table 3). During the next year as a result of natural widespread influenza $\mathrm{A}(\mathrm{H} 1 \mathrm{~N} 1)$ pdm 09 virus circulation and vaccination of the population, immunity increased up to $36.2 \%$ in October 2010, but didn't achieve the level typical for immunity against seasonal influenza viruses. This contributed to the development of the second pandemic wave. As a result, further increase of population immunity to the pandemic virus $(54.3 \%$ of population acquired protective titers of antibody by April 2011) was registered. A decrease of immunity to influenza $\mathrm{A}(\mathrm{H} 3 \mathrm{~N} 2)$ virus which didn't circulate during the two previous seasons was found in October 2011 (geometric mean titers decreased from 43 to 35.3 and the percent of people with protective titers of antibody decreased from 68 to $58 \%$ ). This decrease in immunity in $\mathrm{H} 3 \mathrm{~N} 2$, promoted reappearance in circulation of influenza $\mathrm{A}(\mathrm{H} 3 \mathrm{~N} 2)$ viruses throughout the country. Low epidemic 
activity of influenza virus A(H1N1) pdm 09 in the 20112012 season was observed. However, it should be noted that intensity of morbidity caused by influenza A(H3N2) virus this season was significantly lower than in all previous seasons of the pre- pandemic period.

\subsection{Antigenic analysis of the Russian isolates}

For all seven years reported, the WHO NIC at RII continued to isolate influenza viruses both in MDCK and chicken embryos routinely. Three influenza A viruses (H1N1, H1N1 pdm 09, H3N2) and influenza B of two lineages (Yamagata and/or Victoria) circulated during five epidemics and two pandemic waves for the reported period.

\subsection{Influenza A(H1N1) Viruses}

Influenza $\mathrm{A}(\mathrm{H} 1 \mathrm{~N} 1)$ viruses were isolated in MDCK cells and chicken embryos as well. For the 2007-2008 season $82.6 \%$ of strains were isolated in eggs or in parallel in eggs and MDCK cells. The proportion of epidemic H1N1 strains varied from 12 to $37 \%$ in the prepandemic period. Since the 2009-2010pandemic seasonH1N1 seasonal viruses disappeared from circulation and were replaced by the pandemic strain (Table 2). Antigenic analysis showed that Russian strains followed the general global trend in evolution: New Caledonia/20/99 $\rightarrow$ SolomonIslands/03/06 $\rightarrow$ Brisbane/59/ $07 \rightarrow$ Hong Kong $/ 1870 / 08$. However, in the last three years of circulation influenza A(H1N1) virusesevolvedmore actively than in the previous period and formed 2-3 antigenic ally distinct groups each season (Konovalova et al., 2010).

\subsection{Pandemic Influenza A(H1N1) pdm 09 Viruses}

The first pandemic influenza A(H1N1) pdm 09 viruses were isolated in May-July 2009 from patients arriving from the USA and Spain. However, regular isolation of viruses began in October 2009 and lasted until April 2010. The isolation of influenza $\mathrm{A}(\mathrm{H} 1 \mathrm{N1})$ pdm 09 viruses in eggs was more efficient than in MDCK cells, especially in autopsy sample investigations.

For antigenic analysis of pandemic viruses antis era to influenza A/California/07/09(H1N1) pdm 09, A/St.Petersburg/56/09 (H1N1) pdm 09, A/New Jersey/8/76 (Hsw1N1), A/swine/1976/31(Hsw1N1) and A/swine/Iowa/30 (Hsw1N1) strains were prepared at RII. All new strains isolated in Russia antigenic ally were A/California/07/09-like. No specific antigenic changes were detected among viruses isolated from autopsy or clinical materials. Only two strains from the total number of viruses isolated were evaluated as drift-variants of A/California/07/09 because of a decreased level of interaction with specific antibodies. Interestingly pandemic isolates reacted with antis era to viruses such as A/New/Jersey/8/76, A/swine/1976/31, A/Iowa/15/30 to $1 / 4$ or $1 / 8$ of homologous titers and for some viruses even to $1 / 2$ of initial titer. In the 2010-2011 epidemic season most (53\%) of the isolates formed a homogenous group of A/California/07/09-like viruses that reacted with antis era to A/St.-Petersburg/56/09 and to A/South Carolina/20/10 up to $1-1 / 2$ of homologous titer as well. No specific antigenic changes were detected among isolates of influenza A(H1N1) pdm 09 virus from of the 2011-2012 season.

\subsection{Influenza $A(H 3 N 2)$ Viruses}

For the described period all Russian influenza $\mathrm{A}(\mathrm{H} 3 \mathrm{~N} 2)$ viruses were isolated only in MDCK cells because H3N2 viruses became much more difficult to isolate in embryonated hen's eggs. In the 2005/2006 epidemic season when $57 \%$ of the strains were of influenza $\mathrm{A}(\mathrm{H} 3 \mathrm{~N} 2)$ virus subtype no significant antigenic drift was found and only slightly reduced relationships with isolates of the previous years were observed. Russian strains reacted well with antisera to the reference strain $\mathrm{A} / \mathrm{Wisconsin} / 67 / 05$ and to the local representative virus A/St.-Petersburg/71/07. In the 2006-2007 season influenza $\mathrm{A}(\mathrm{H} 3 \mathrm{~N} 2)$ viruses were estimated at $41 \%$ of all strains isolated in Russia and again with no significant antigenic changes. In the 2007-2008 season the proportion of influenza $\mathrm{A}(\mathrm{H} 3 \mathrm{~N} 2)$ viruses decreased and they were more heterogeneous in antigenic properties. About $40 \%$ of the isolates acquired characteristics of the new reference strain $\mathrm{A} /$ Brisbane/10/07 and the other group of viruses interacted in low HI titers both with antisera to the new and to the previous reference and circulating epidemic strains. Circulation of these viruses continued in the next (20082009) season when they accounted for $49 \%$ of all isolates. Most viruses proved to be drift-variants of the reference strain A/Brisbane/10/07. However, about $30 \%$ of the characterized strains interacted with this antiserum to the lower titer. During the first pandemic wave in the 20092010 season, H3N2 subtype practically disappeared from circulation in Russia and only $7 \%$ of viruses were H3N2during the second pandemic wave in 2010-2011. In the 2011-2012 season influenza A(H3N2) virus which returned to circulation became the dominant strain $(66 \%$ of all isolates). A majority of the viruses interacted with antiserum to the reference strain A/Perth/16/09 and other isolates reacted with antisera to viruses of Perth-like group to low titers and were closer in antigenic properties to A/Victoria/210/09. All of the viruses reacted with ferret 
antiserum to the new reference strain A/Victoria/361/11but only to $1 / 8-1 / 16$ titers with rat antiserum to this new virus recommended to be included in the influenza vaccine composition for the 2012-2013 season. Nevertheless, the majority of Russian isolates reacted most effectively (up to $1 / 2$ of homologous titer) with antiserum to the $\mathrm{A} / \mathrm{St}$.-Petersburg/10/12 strain (which was representative for the Russian isolates) and with WHO/CDC diagnostic serumtoinfluenza A(H3N2) virus. We found only a slight and gradual antigenic drift until 2011-2012 when more evolution among influenza A(H3N2) viruses circulating in Russia occurred.. During the period studied, Russian H3N2 viruses generally compared well with the viruses adopted by WHO experts as the reference strains: $\mathrm{A} /$ Wisconsin/67/05 $\rightarrow \mathrm{A} /$ Brisbane $/ 10 / 07 \rightarrow$ drift variants of $\mathrm{A} /$ Brisbane/10/07 $\rightarrow \mathrm{A} /$ Perth/16/09 $\quad(\mathrm{A} / \mathrm{Wisconsin} / 15 / 09$, $\mathrm{A} /$ Victoria/208/09) $\rightarrow$ A/Victoria/361/11.

\subsection{Influenza $B$ viruses}

During the study period influenza epidemics in the Russian Federation were characterized by regular circulation of influenza B viruses during the epidemic periods. It is important to note that influenza $\mathrm{B}$ viruses, unlike influenza $\mathrm{A}(\mathrm{H} 3 \mathrm{~N} 2)$ viruses, maintained their capability to replicate effectively not only in MDCK cells but in chicken embryos as well. This is an important trait in terms of strain selection for influenza vaccines (Ivanova et al., 2011).

All influenza B strains isolated during the 2005-2006 season belonged to the Victoria lineage and formed an antigenic ally homogenous group. Viruses interacted to $1-1 / 2$ of homologous titers with antiserum to the reference strain B/Malaysia/2506/04 which was recommended for inlcusion in influenza vaccines for the Northern hemisphere 2006-2007season.

In the 2006-2007 season both Victoria and Yamagata influenza B lineages circulated in Russia, though Yamagata lineage strains were isolated rarely and only in two cities. All influenza B viruses of Victoria lineage were antigenic ally similar to the influenza B/Malaysia/2506/04 virus. Only 4 viruses which belonged to the Yamagata lineage and were B/Florida/07/04-like viruses. In the 2007-2008 season the situation changed radically. Yamagata lineage predominated throughout the epidemic season and all the viruses isolated in this period were antigenic ally related to B/Florida/07/04 virus with the exception of two Victorialike B viruses which were isolated in late May 2008 and were similar to B/Malaysia/2506/04. The re-emergence of
Victoria viruses at the end of epidemic season indicated that they could be the causative epidemic agents next season. Indeed, in 2008-2009 only B-Victoria like viruses spread in Russia. This season was characterized by an antigenic drift of influenza B virus which wasn't evident earlier. Viruses didn't react with antiserum to the reference strain B/Malaysia/2506/04or to B/FujianGulou/1272/08 and were reactive specifically with antiserum to the $\mathrm{B} / \mathrm{Brisbane} / 60 / 08$ strain.

After the pandemic of the 2009-2010 season in March-May, 2010 a number of influenza B viruses were isolated. Most of them were B/Brisbane/60/08like. Surprisingly, it was found that few isolates reacted with antisera to B/Fujian-Gulou/1272/08 and $\mathrm{B} /$ Malaysia/2506/04 which was different from observationsin viruses during the previous season. In the 2010-2011 season influenza B appeared in circulation earlier than usual (in December 2010) and all of them belonged to the Victoria lineage and were similar to the reference strain B/Brisbane/60/08. In the2011-2012 season simultaneous circulation of Yamagata and Victoria lineage viruses was observed in Russia (21.2 and $78.8 \%$ of all influenza B isolates, respectively) as in other countries of the Europe. Victorian strains were B/Brisbane/60/08-like and Yamagata strains were antigenic ally related to $\mathrm{B} /$ Bangladesh/3333/07 or B/Wisconsin/01/10 viruses.

\subsection{Determination of Virus Susceptibility to Antivirals for 7-years Period}

Monitoring circulating influenza viruses' susceptibility to oseltamivir, zanamivir and rimantadine is an important part of influenza surveillance and necessary for understanding the global spread of strains resistant to antivirals. These data guide recommendations for influenza treatment.

Testing of viruses for susceptibility to antivirals indicated a gradual growth in the percent of rimantadine resistant influenza $\mathrm{A}(\mathrm{H} 3 \mathrm{~N} 2)$ viruses during the reported period which reached $90-100 \%$ during the last four seasons. A low percent of viruses were resistant to oseltamivir. For seasonal influenza $\mathrm{A}(\mathrm{H} 1 \mathrm{~N} 1)$ viruses, an increased proportion of oseltamivir resistant strains was observed during the 2006-2007 and 2008-2009 influenza seasons, after which this virus disappeared from circulation. All tested pandemic influenza $\mathrm{A}(\mathrm{H} 1 \mathrm{~N} 1)$ pdm09 viruses isolated since the 2009-2010 and 2011-2012 seasons appeared to be resistant to rimantadine but susceptible to oseltamivir and zanamivir (Table 4). 
Sominina Anna et al. / American Journal of Infectious Diseases 9 (3): 77-93, 2013

Table 4. Cumulative results of Russian influenza A viruses testing for susceptibility to antivirals in two WHO NICs during the period 2005-2012

\begin{tabular}{|c|c|c|c|c|c|c|c|c|}
\hline \multirow[b]{2}{*}{ Virus subtype } & \multirow{2}{*}{$\begin{array}{l}\text { Antiviral } \\
\text { drugs }\end{array}$} & \multicolumn{7}{|c|}{ Number and percent of influenza A viruses resistant to antiviral drugs } \\
\hline & & $2005 / 06$ & $2006 / 07$ & $2007 / 08$ & $2008 / 09$ & $2009 / 10$ & $2010 / 11$ & $2011 / 12$ \\
\hline \multirow[t]{3}{*}{$\mathrm{A}(\mathrm{H} 3 \mathrm{~N} 2)$} & Rimantadine & $\begin{array}{l}51 / 98 \\
(52.0)\end{array}$ & $\begin{array}{l}74 / 132 \\
(56.1)\end{array}$ & $\begin{array}{l}38 / 60 \\
(63.3)\end{array}$ & $\begin{array}{l}128 / 142 \\
(90.1)\end{array}$ & 0 & $\begin{array}{l}3 / 3 \\
(100)\end{array}$ & $\begin{array}{l}114 / 114 \\
(100)\end{array}$ \\
\hline & Oseltamivir & $\begin{array}{l}0 / 7 \\
(0.0)\end{array}$ & $\begin{array}{l}3 / 96 \\
(3.1)\end{array}$ & $\begin{array}{l}0 / 50 \\
(0.0)\end{array}$ & $\begin{array}{l}1 / 22 \\
(4.5)\end{array}$ & 0 & $\begin{array}{l}0 / 11 \\
(0.0)\end{array}$ & $\begin{array}{l}0 / 119 \\
(0.0)\end{array}$ \\
\hline & Zanamivir & nt & nt & $\begin{array}{l}0 / 31 \\
(0.0)\end{array}$ & nt & 0 & $\begin{array}{l}0 / 3 \\
(0.0)\end{array}$ & $\begin{array}{l}0 / 106 \\
(0.0)\end{array}$ \\
\hline \multirow[t]{3}{*}{$\mathrm{A}(\mathrm{H} 1 \mathrm{~N} 1)$} & Rimantadine & $\begin{array}{l}21 / 82 \\
(25.6)\end{array}$ & $\begin{array}{l}45 / 86 \\
(52.3)\end{array}$ & $\begin{array}{l}39 / 169 \\
(23.1)\end{array}$ & $\begin{array}{l}46 / 173 \\
(26.5)\end{array}$ & 0 & 0 & 0 \\
\hline & Oseltamivir & $\begin{array}{l}0 / 25 \\
(0.0)\end{array}$ & $\begin{array}{l}8 / 30 \\
(26.7)\end{array}$ & $\begin{array}{l}100 / 127 \\
(78.8)\end{array}$ & $\begin{array}{l}243 / 275 \\
(88.4)\end{array}$ & 0 & 0 & 0 \\
\hline & Zanamivir & $\mathrm{nt}$ & $\mathrm{nt}$ & $\begin{array}{l}0 / 21 \\
(0.0)\end{array}$ & $\begin{array}{l}0 / 7 \\
(0.0)\end{array}$ & 0 & 0 & 0 \\
\hline \multirow[t]{3}{*}{$\begin{array}{l}\text { A(H1N1 } \\
\text { pdm09 }\end{array}$} & Rimantadine & 0 & 0 & 0 & nt & $\begin{array}{l}52 / 52 \\
(100)\end{array}$ & $\begin{array}{l}58 / 58 \\
(100)\end{array}$ & $\mathrm{nt}$ \\
\hline & Oseltamivir & 0 & 0 & 0 & $\begin{array}{l}0 / 2 \\
(0.0)\end{array}$ & $\begin{array}{l}1 / 95 \\
(1.0)\end{array}$ & $\begin{array}{l}0 / 160 \\
(0.0)\end{array}$ & $\begin{array}{l}0 / 3 \\
(0.0)\end{array}$ \\
\hline & Zanamivir & 0 & 0 & 0 & $\mathrm{nt}$ & $\begin{array}{l}0 / 48 \\
(0.0)\end{array}$ & $\begin{array}{l}0 / 58 \\
(0.0)\end{array}$ & $\mathrm{nt}$ \\
\hline
\end{tabular}

Note: Percent of viruses resistant to antiviral drug is indicated in brackets; nt-no tested viruses; 0-no viruses of subtype indicated were isolated during the reported season

\subsection{Primary Results of Sentinel Surveillance in RUSSIA for the Period Since the 2010-2011 to 2011-2012 Seasons}

The traditional system of influenza surveillance is not comprehensive and does not provide information about the causes of severe influenza or clinical course in humans and the impact of specific prevention and antiviral treatment options. In order to enhance surveillance since 2010, the traditional system was supplemented by sentinel sites and laboratory Surveillance (SS) adopted in the WHO European Region system (WHO, 2009). Since the 2010-2011 season SS was introduced in 9 geographically distant cities of the Russian Federation. The sites provide laboratory analysis of materials from patients hospitalized with severe influenza (SARI) as well as in outpatient ILI and ARI cases, followed by detailed anamnestic data for age, concomitant diseases, status of influenza vaccination and prior antiviral therapy.

The analysis of the etiology of morbidity in these groups of patients using rRT-PCR in the 2010-2011 and 2011-12 epidemic seasons, showed laboratory diagnosis of influenza obtained in the SS system, to be comparable to the results of extended Traditional Etiological influenza Monitoring (TEM). In the 2010-2011 season the etiological structure of influenza as with SARI and ILI/ARI cases showed predominance of influenza $\mathrm{A}(\mathrm{H} 1 \mathrm{~N} 1)$ pdm 09 virus (in 65 and $61 \%$ cases, respectively), while influenza $\mathrm{B}$ was diagnosed less frequently (in 26 and 24\%, correspondingly). During the influenza epidemic peak 2011-2012 influenza A viruses caused $86 \%$ of SARI cases including $81 \%$ of $\mathrm{A}(\mathrm{H} 3 \mathrm{~N} 2)$ and $5 \%$ of $\mathrm{A}(\mathrm{H} 1 \mathrm{~N} 1)$ pdm 09 agents, whereas in ILI/ARI patients influenza A was diagnosed in $63 \%$ of cases. Influenza B virus was found less frequently in SARI ( $14 \%$ of cases) whereas in ILI/ARI patients influenza B was detected in $36 \%$ of cases.

The rate of laboratory-confirmed influenza in SS at the peak of the 2010-2011 influenza season reached up to $55.7 \%$ in SARI and to $45.3 \%$ in ILI/ARI cases and was slightly lower in the season 2011-2012 (50.0\% in SARI and $35.0 \%$ in ILI/ARI cases). The number of patients with influenza among all SARI cases for the 2011-12 season was lower than in the epidemic of 20102011 (12 and $19 \%$ of patients, respectively).

Analysis of data on underlying conditions in influenza and non-influenza SARI cases, shows the significance of pregnancy and cardiovascular system diseases in the development of SARI. However among patients with SARI caused by influenza A virus in both epidemic seasons, regardless of virus subtype, pregnancy was the leading risk factor for SARI developing (23.7\% in $2010-2011$ and $32.2 \%$ in 2011 2012.). Cardiovascular diseases were documented in $4.7 \%$ and $5.5 \%$ of SARI cases in the 2010-2011 and 2011-2012 seasons, respectively (Fig. 7). 


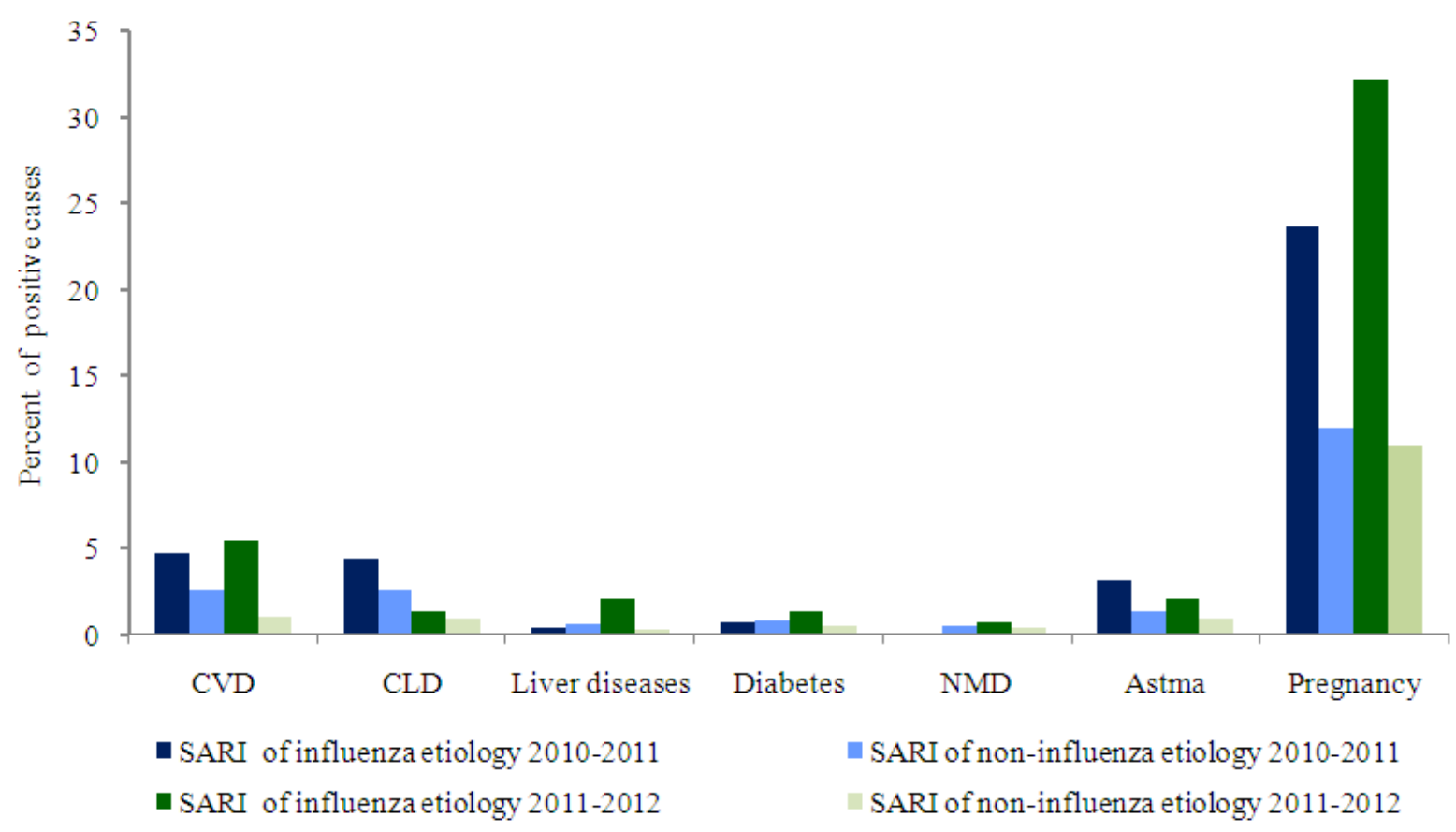

Fig. 7. Comparative data on structure of underlying conditions in influenza and non-influenza SARI cases, seasons2010-2011 and 2011-2012; Note: Cardiovascular Diseases (CVD), Chronicle Lung Diseases (CLD), Neuromuscular Dysfunction (NMD)

The proportion of SARI patients with confirmed influenza with concomitant diseases was much higher than non-influenza SARI patients (42 and $21 \%$ in 2010 2011, 32 and $11 \%$ in 2011-2012, respectively). In both epidemic seasons a very small percentage $(4 \%)$ of SARI patients with influenza was vaccinated and this suggest for increased risk of SARI development among unvaccinated individuals.

\section{DISCUSSION}

The 7-year longitudinal study covers the prepandemic period (seasons from 2005-06 to 2008-09), characterized by moderate influenza activity associated with co-circulation of influenza $\mathrm{A}(\mathrm{H} 1 \mathrm{~N} 1), \mathrm{A}(\mathrm{H} 3 \mathrm{~N} 2)$ and $B$ viruses in different proportions, two pandemic seasons (2009-10 and 2010-11) when influenza A(H1N1) pdm 09 dominated and caused unusually high morbidity and mortality in Russia, as well as one post-pandemic season (2011-12)with very low morbidity associated with influenza $\mathrm{A}(\mathrm{H} 3 \mathrm{~N} 2)$ and $\mathrm{B}$ viruses circulating. It is well known that the emergence of a new pandemic virus is unpredictable. The appearance of a new pandemic $\mathrm{A}(\mathrm{H} 1 \mathrm{~N} 1)$ pdm 09 virus in Mexico in 2009 was rather unexpected. Soon after isolation of the new triple reassortant influenza $\mathrm{A}(\mathrm{H} 1 \mathrm{~N} 1)$ pdm 09 virus in California (USA) and its identification in CDC (Atlanta, USA) it was established that the novel virus differed significantly from circulating seasonal $\mathrm{A}(\mathrm{H} 1 \mathrm{~N} 1)$ viruses. In our investigations the antigenic properties of the emergent virus was found to be more closely related to $\mathrm{A} /$ swine/Iowa/15/1930 and $\mathrm{A} /$ swine/1976/31 viruses which circulated in swine populations in the 1930s (after the severe "Spanish flu" pandemic in 1917-1918)as well as to the A/New Jersey/07/1976 virus, which was the virus that caused an outbreak among military recruits in the USA in 1976. Thus, even though more than 90 years have passed since the emergence of viruses of the "Spanish flu" era, the hem agglutinin of those viruses and the strains of pandemic 2009 saved common antigenic determinants (Eropkin et al., 2011; Sominina et al., 2011). The co-crystal structure of the 1918 hem agglutinin with 2D1, an antibody from a survivor of the 1918 Spanish flu, that neutralizes both 1918 and 2009 H1N1 viruses, reveals an epitope that is conserved in both pandemic viruses (Xu et al., 2010).

Great contribution to the development of the theory of pandemic influenza virus origin was made by Taubenberger et al. (2012) who reconstructed and investigated the "Spanish" virus after step-by-step 
recognition of its genome structure. As it was shown in the investigation of Sominina et al. (2011) the 1918 pandemic virus was genetically and antigenically most closely related to influenza virus A/swine/Iowa/15/1930.

It is appropriate to note that the emergence of the new A (H1N1) pdm09 virus conforms to the hypothesis of the academician Anatoly A. Smorodintsev regarding the high probability of reappearance of the "Spanish flu" virus in circulation among humans after a decrease of population immunity levels to this virus as a result of the decrease of the percent of elderly people with immunity to this virus (Smorodintsev, 1984). Many years of investigations performed by RII in collaboration with RVLs showed that the population immunity to influenza $\mathrm{A} /$ swine /Iowa/30 virus as well as to influenza $\mathrm{A}(\mathrm{H} 2 \mathrm{~N} 2)$ and $\mathrm{A}(\mathrm{H} 5 \mathrm{~N} 1)$ viruses became very low. After two pandemic waves population immunity to influenza $\mathrm{A}(\mathrm{H} 1 \mathrm{~N} 1)$ pdm 09 virus increased significantly while its decrease to influenza $\mathrm{A}(\mathrm{H} 3 \mathrm{~N} 2)$ resulted in spread of recent $\mathrm{H} 3 \mathrm{~N} 2$ virus in Russia during the 2011-2012 season.

The interesting question is why do the new pandemic viruses usually displace the preceding seasonal influenzaA viruses from circulation? Pandemic influenza $\mathrm{A}(\mathrm{H} 1 \mathrm{~N} 1)$ pdm 09 virus spread led to the rapid disappearance of the seasonal $\mathrm{A}(\mathrm{H} 1 \mathrm{~N} 1)$ virus. One of the possible mechanisms could be associated with increased capacity of a newly emerging influenza virus for rapid transmission partly associated with low population immunity to this virus. Only $10.1 \%$ of the Russian population had protective antibody titers to the pandemic virus in October 2009. This is different from the seasonal $\mathrm{A}(\mathrm{H} 1 \mathrm{~N} 1)$ virus against which about $66 \%$ of population were protected. The data on low immunity level to influenza $\mathrm{A}(\mathrm{H} 1 \mathrm{~N} 1)$ pdm 09 virus in the Russian population in 2009 is consistent with the data of Hancock et al. (2009) obtained in the USA. This gave the pandemic virus the advantage over the seasonal $\mathrm{A}(\mathrm{H} 1 \mathrm{~N} 1)$ virus to spread easily among humans with displacement of the latter from circulation. Capacity of influenza $\mathrm{A}(\mathrm{H} 3 \mathrm{~N} 2)$ virus to cause epidemics in the following seasons was preserved. It might be explained by published data indicating different evolutionary dynamics exhibited by influenza $\mathrm{A}(\mathrm{H} 1 \mathrm{~N} 1)$ and $\mathrm{A}(\mathrm{H} 3 \mathrm{~N} 2)$ viruses (Bhatt et al., 2011).

Comparative analysis of epidemics' intensity and etiology for the seven years' period indicated that the highest morbidity peaks were registered exactly in pandemic seasons 2009-2010 (Karpova et al., 2010) and 2010-2011 and exceeding peak morbidity indices of those usually recorded during seasonal epidemics by 1.3-1.6 times. Sharp growth of hospitalization and mortality cases was recorded during the two consecutive pandemic waves as well.

As in other countries, the main causes of deaths associated with influenza appeared to be pregnancy, chronic cardiovascular and respiratory tract diseases and obesity. Changes in the age structure of morbidity and mortality were found during the pandemic as well. Different from seasonal epidemics, the highest morbidity level was registered among schoolchildren and socially active groups of employable populations.

Periodic substitution of influenza B viruses belonging to Victoria lineage by Yamagata lineage (2007-2008 season) and contrariwise (2008-2009) which was difficult to predict in time lead to challenges for determining vaccine strain composition for the Northern hemisphere. As indicated above, two seasons showed a mismatch of circulating influenza $B$ viruses and the influenza B component of the vaccine. For this reason a number of vaccine manufacturers decided to produce tetra-vaccines including representatives of both contemporary lineages of influenza B virus starting with the 2012-2013 season.

Introduction of sentinel surveillance in Russia, in addition to routine epidemiological approaches, yielded new results regarding the percent of influenza associated SARI cases where influenza A virus subtype dominated in etiology of morbidity during epidemics. It is interesting that dring the 2011-12 season when influenza $\mathrm{A}(\mathrm{H} 3 \mathrm{~N} 2)$ predominated the number of patients with influenza among all SARI cases was lower than in the second wave of influenza pandemic 2010-2011 (12 and 19\% of patients, respectively).. These investigations also showed an increased threat of severe influenza development among pregnant women and evidence to include them as a risk group for vaccination. In addition, results of sentinel surveillance showed that only $4 \%$ of patients in influenza associated SARI cases were vaccinated. According to the official data of Rospotrebnadzor (Press-release: "On the course of influenza vaccination in the Russian Federation and the incidence of influenza and ARI" from 12.12.2012) "The total number of vaccinated against influenza is more than 36.3 million people $(25.4 \%$ of the total population)."This supportsthe importance of vaccination for priority groups of risk, which in this investigation were determined as pregnant women and patients with cardiovascular and chronicle lung diseases.

\section{CONCLUSION}

In 2009, the world saw the unexpected emergence of influenza $\mathrm{A}(\mathrm{H} 1 \mathrm{~N} 1)$ pdm09 virus in North American 
countries (Mexico, USA) followed by the rapid development of a global pandemic . In Russia the first pandemic wave was characterized by rapid growth of morbidity with an unusually high level of hospitalization and mortality. The pandemic followed four seasons of usual moderate influenza activity associated with circulation of seasonal influenza $\mathrm{A}(\mathrm{H} 1 \mathrm{~N} 1), \mathrm{A}(\mathrm{H} 3 \mathrm{~N} 2)$ and $\mathrm{B}$ viruses. The pandemic started in Russia during week 40. 2009 with sporadic cases of illness caused by $\mathrm{A}(\mathrm{H} 1 \mathrm{~N} 1)$ pdm09 virus among people arriving from affected countries were the pandemic beganin May-June 2009. A second pandemic wave developed as usual for seasonal epidemics during winter 2010, with the level of morbidity and mortality below that documented during the first pandemic wave. Decreased morbidity and mortality was associated with a rise in population immunity.

Analysis of antigenic and genetic properties of influenza viruses circulating in Russia during the period 2006-2012 showed the relation to the strains recommended by WHO for vaccine composition for the Northern hemisphere with the exception of two seasons when an unexpected replacement of the influenza B viruses of Victoria lineage by Yamagata lineage (20072008) and vice versa was observed. The enhancement of influenza surveillance in Russia was a result of the wide introduction of rRT-PCR diagnosis, regular testing of influenza viruses for susceptibility to antivirals, phylogenetic analysis as well as organization of sentinel surveillance in a number of Regional Base Laboratories. Improvements promoted the rapid recognition of the introduction of the new pandemic virus in the country and enhancement of laboratory confirmation tests enabled the determination of influenza associated risk groups for SARI and fatal cases.

\section{ACKNOWLEDGEMENT}

This study was supported in part by BTEP ID \#107 grant, by Cooperative Agreement under DHHS \#1U51IP000527-01, by the Russian Academy of Medical Sciences and the Ministry of Public Health of Russian Federation. We thank all RBLs of NICs for close collaboration in influenza surveillance in Russia. We thank John Wood (NIBSC, UK) for influenza reassortant strain NIBRG-14 presentation, Caroline Brown and Tomas Vega (WHO/EURO) for assistance in the sentinel surveillance introduction and influenza baseline determination for Russia.

\section{REFERENCES}

Bhatt S., E.C. Holmes and O.G. Pybus, 2011. The genomic rate of molecular adaptation of the human influenza A virus. Mol. Biol. Evol., 28: 2443-2451. DOI: $10.1093 / \mathrm{molbev} / \mathrm{msr} 044$

Eropkin, M.Y., D.M. Danilenko, N.I. Konovalova, A.V. Ivanova and T.M. Gudkova et al., 2011. Pandemic influenza 2009 in Russia: Isolation, antigenic analysis and biological properties of viruses. Influenza Other Respiratory Viruses, 5: 416-418. DOI: $10.1111 /$ j.1750-2659.2011.00225x

Guo, L., R.J. Garten, A.S. Foust, W.M. Sessions and M. Ikomo-Adhiambo et al., 2009. Rapid identification of oseltamivir-resistant influenza $\mathrm{A}(\mathrm{H} 1 \mathrm{~N} 1)$ viruses with H274Y mutation by RT-PCR/restriction fragment length polymorphism assay. Antiviral Res., 82: 29-33. DOI: 10.1016/j.antiviral.2009.01.004

Hancock, K., V. Veguilla, X. Lu, W. Zhong and E.N. Butler et al., 2009. Cross-reactive antibody responses to the 2009 pandemic H1N1 influenza virus. New Engl. J. Med., 361: 1945-1952. DOI: 10.1056/NEjMoa0906453

Ivanova, A.V., D.M. Danilenko, T.G. Lobova, T.M. Gudkova and V.A. Grigorieva et al., 2011. Antigenic and biological properties of influenza type B viruses isolated in Russia in 2006-2010. Epidemiol. Vaccinoprophilaktika, 1: 4-8.

Karpova, L.S., I.G. Marinich, T.P. Stolyarova and N.M. Popovtseva, 2010. Analysis of influenza epidemic A/California/07/2009 (H1N1) in Russia during the season 2009-2010. Epidemiol. Vaccinoprophilaktika, 3: 23-30.

Konovalova, N.I., M.Y. Eropkin, T.M. Gudkova, V.A. Grigorieva and D.M. Danilenko et al., 2010. Etiological characteristics of the influenza epidemics 2006-2009 in the Russian Federation. Voprosy Virusol., 55: 9-16. PMID: 20886706

Lvov, D.K., E.I. Burtseva, A.G. Prilipov, M.V. Bazarova and L.V. Kolobukhina et al., 2009. The 24 May, 2009 isolation of the first A/IIV-Moscow/01/2009 (H1N1)swl strain similar to swine $\mathrm{A}(\mathrm{H} 1 \mathrm{~N} 1)$ influenza virus from the first Moscow case detected on May 21, 2009 and its deposit in the State Collection of Viruses (SCV No.2452 dated May 24, 2009). Voprosy Virusol., 54: 10-14. PMID: 19882896 
Pica, N., R. Hai, F. Krammer, T.T. Wang and J. Maamary et al., 2012. Hemagglutinin stalk antibodies elicited by the 2009 pandemic influenza virus as a mechanism for the extinction of seasonal H1N1 viruses. PNAS, 109: 2573-2578. DOI: 10.1073/pnas.1200039109

Smee, D.F., B.L. Hurst, M.H. Wong, K.W. Bailey and J.D. Morrey, 2009. Effects of double combinations of amantadine, oseltamivir and ribavirin on influenza A (H5N1) virus infections in cell culture and in mice. Antimicrob. Agents Chemother., 53: 2120-8. DOI: 10.1128/AAC.01012-08

Smorodintsev, A.A., 1984. Origin of Pandemic Strains of Influenza a Virus. In: Influenza and its Prophylaxis, Medicine, Leningrad, pp: 113-138.

Sominina, A.A., M.P. Grudinin, M.I. Eropkin, L.S. Karpova and M.M. Pisareva et al., 2011. Analysis of pandemic influenza in Russia as part of the global process based on data of the influenza monitoring reference center. J. Microbiol. Epidemiol. Immunobiol., 3: 20-26. PMID21809641
Taubenberger, J.K., D. Baltimore, P.C. Doherty, H. Markel and D.M. Morens et al., 2012. Reconstruction of the 1918 influenza virus: Unexpected rewards from the past. mBio, 3: e00201- e00212. DOI: 10.1128/mBio.00201-12

CDCP, 2011. Update: Influenza activity---United States, 2010--11 Season and composition of the 2011--12 influenza vaccine. Centers for Disease Control and Prevention.

WHO, 2009. WHO Regional Office for Europe Guidance for Sentinel Influenza Surveillance in Humans. WHO/Europe Press, Copenhagen, Denmark, pp: 80.

WHO, 2011. Use of neuraminidase inhibition assays to determine the susceptibility of influenza viruses to antiviral drugs. Manual for the laboratory diagnosis and virological surveillance of influenza pp.103-115.

$\mathrm{Xu}$, R., D.C. Ekiert, J.C. Krause, R. Hai and J.E. Crowe Jr. et al., 2010. Structural basis of preexisting immunity to the $2009 \mathrm{H} 1 \mathrm{~N} 1$ pandemic influenza Virus. Science, 328: 357-360. DOI: 10.1126/science. 1186430 